\title{
Inventário de Enobares de São Paulo (São Paulo, Brasil) e perfil de seus frequentadores
}

\section{Wine Bars Inventory in São Paulo (São Paulo, Brazil) and profile of the costumers}

\author{
Bruna Eliza Previatello Peçanha (PEÇANHA, B. E. P.)*, \\ Camila Alberto Augusto (AUGUSTO, C. A.) $)^{* *}$, \\ Caroline Galvão Nery (NERY, C. G.) ${ }^{\text {**** }}$, \\ Jaqueline Letícia Mesquita Silva Oda (ODA, J. L. M. S.) ${ }^{* * * * *}$, \\ Julio Cesar Souza Santos (SANTOS, J. C. S.) ${ }^{* * * * *}$ e \\ Alexandre Panosso Netto (PANOSSO NETTO, A.) ${ }^{* * * * * * *}$
}

RESUMO - Compreender o turismo como fenômeno crescente na sociedade atual é primordial quando se pretende entender as transformações e particularidades sociais decorrentes da vontade de experienciar novas vivências, como é o caso da degustação de vinhos em enobares. A presente pesquisa visou contribuir com o assunto, por meio

\footnotetext{
* Formação: Discente do Curso de Lazer e Turismo da Escola de Artes, Ciências e Humanidades da Universidade de São Paulo (EACH-USP). Bolsista do Programa Institucional de Bolsas de Iniciação Científica (PIBIC) com o projeto "Mapeamento das variáveis ambientais nas práticas de lazer na zona leste da cidade de São Paulo" e participante da pesquisa "Mapeamento dos Lazeres dos Brasileiros". Endereço físico para correspondência: Rua Luzia Balzani, 235, ap. 116, Vila Moreira. CEP: 07020-021 Guarulhos - São Paulo (Brasil). Telefone: (11) 2441-0678 / (11) 98134-8732. E-mail: brunaprevi@gmail.com

*** Formação: Discente do Curso de Lazer e Turismo (EACH-USP). Bolsista do Programa Institucional de Bolsas de Iniciação Científica (PIBIC) com o projeto "eMarketing da Agência Flytour Viagens". Endereço físico para correspondência: Rua Caracol, 70, Penha. CEP: 03642-060 - São Paulo - São Paulo (Brasil). Telefone: (11) 2642-0512 / (11) 99149-5300. E-mail: camila.augusto@usp.br ou camila.alberto@usp.br
}

\footnotetext{
**** Formação: Discente do Curso de Lazer e Turismo (EACH-USP). Bolsista do Programa de Estímulo de Ensino de Graduação (PEEG) na EACH/USP (1ºmestre 2013). Membro do Grupo Interdisciplinar de Estudos do Lazer (GIEL/EACH-USP). Endereço físico para correspondência: Rua Aparecida Guerini Cruz, 49, Jardim Clementino. CEP: 06770-260 - Taboão da Serra - São Paulo (Brasil). Telefone: (11) 4137-7139 / (11) 96556-2128. E-mail: caroline.nery@usp.br

Formação: Discente do Curso de Lazer e Turismo (EACH-USP). Bolsista do Programa de Tutoria Científico Acadêmica com o projeto "Megaeventos esportivos". Membro do Grupo Interdisciplinar de Estudos do Lazer (GIEL/EACH-USP). Endereço físico para correspondência: Rua do Sacramento, 581, ap. 41, Rudge Ramos. CEP: 09640-000 - São Bernardo do Campo - São Paulo (Brasil). Telefone: (11) 4368-1495 / (11) 99134-2503. E-mail: jaqueline.oda@usp.br
}

\footnotetext{
Formação: Discente do Curso Lazer e Turismo (EACH-USP). Trainee na Empresa Junior de Lazer e Turismo (EACH-USP) e bolsista no Programa Ensinar com Pesquisa da Pró-Reitoria de Graduação (USP). Endereço físico para correspondência: Rua Padre Mariano Ronchi, 1280. CEP: 02932-000 Pirituba - São Paulo - São Paulo (Brasil). Telefone: (11) 3991-3904 / (11) 98833-9436. E-mail: julio.cesar.santos@usp.br

Formação: Pós-doutorado em turismo pela Universidad Europea Miguel de Cervantes, em Valladolid (Espanha) e Livre-Docência em Teorias do Turismo pela EACH-USP. Professor, com dedicação exclusiva (EACH/USP). Tem experiência na área de Turismo, com ênfase em Teoria do Turismo. Endereço físico para correspondência: Avenida Arlindo Bettio, 1000. Ermelino Matarazzo. CEP: 03828-000 - São Paulo - São Paulo (Brasil). Telefone: (11) 3091-8878. E-mail: panosso@usp.br
} 
de um inventário que mapeou os principais enobares (restaurantes que possuem o vinho como primeira ou segunda atração principal) na cidade de São Paulo (Brasil), além de identificar o perfil de seus frequentadores. Enquanto metodologia realizou-se pesquisa bibliográfica e empírica de caráter qualitativo: um referencial teórico que trouxesse um breve histórico e conceitos-chave da temática para embasar o estudo, e o inventário desenvolvido utilizando recursos da Web (Google Maps), obtendo assim a localização e informações adicionais dos enobares da cidade. Para análise de perfil dos consumidores, elaboraram-se questionários fechados. A partir da coleta de dados, constatou-se que a maioria dos enobares esteve concentrada na região sul (cerca de 70\%), atendendo um público predominantemente masculino de 30 a 50 anos. Baseando-se no conhecimento e interesse pela bebida, frequência aos enobares, envolvimento em atividades e a presença de adega climatizada em casa, verificou-se que a maioria do público ficou classificado nas categorias casual e interessados.

Palavras-chave: Enoturismo; Enobares; Frequentadores de enobares; São Paulo (Brasil).

ABSTRACT - Understanding tourism as a growing phenomenon of current society is primordial when trying to understand the transformation and social particularities derived from the desire to live new experiences, such as wine tasting in wine bars. This research aimed to contribute to the subject through an inventory that mapped the main wine bars (restaurants that have wine as first or second main attraction) in São Paulo and identified the profile of their customers. The methodology was carried out with literature and empirical research of qualitative type: a theoretical referential that brought a brief history and key concepts of the theme to support the study, and the inventory developed using Web resources (Google Maps), to get the location and additional information about wine bars in the city. To analyze the costumer's profile, closed questionnaires were elaborated. From the data collection, it was found that most wine bars are concentrated in the southern region (about 70\%), attending a predominantly male audience that are around 30-50 years old. Based on knowledge and interest in the drink, the frequency in wine bars, involvement in activities and the presence of wine cellar at home, it was found that most of the public ranks in casual and interested categories.

Key words: Wine tourism; Wine bars; Wine bars’ Costumers; São Paulo (Brazil). 


\section{INTRODUÇÃO}

Reconhecido pelos gregos como a "bebida dos deuses", festejado pelos romanos em homenagem a Baco e considerado produto de status para os egípcios, o vinho se difundiu pelo Oriente Médio, Mediterrâneo e Europa, conquistando povos, significando-se culturalmente e marcando a história da civilização (DALLANHOL; TONINI, 2012).

No Brasil, o cultivo da uva está fortemente associado à expansão territorial dos europeus no processo de colonização, estabelecendo-se já em 1500 (DALLANHOL; TONINI, 2012). Por conseguinte, sua difusão no país fortaleceu-se somente no século XIX e início do XX, principalmente na região sul e sudeste pela similaridade climática europeia (IBRAVIN, 2013, online).

Em São Paulo, sua importância já se verificava em 1640 o qual, mesmo com a produção de um vinho "rude" e de "baixa qualidade", constituía-se como a riqueza da cidade demandando uma padronização da qualidade e preços (MELLO, 2010).

Aprimorando-se com o passar dos anos, principalmente nos últimos 15 anos, a produção foi se solidificando no país e conquistando seu espaço no mercado internacional de vinhos, havendo a necessidade de expandir-se investindo em tecnologias e buscando atender ao paladar da demanda brasileira que se formava (DALLANHOL; TONINI, 2012).

Também, verifica-se neste momento que a produção de vinho amplia-se e integra-se a outras áreas, se configurando em um novo contexto socioeconômico. Dentre estas áreas, ressalta-se o turismo.

Para compreender melhor o desenvolvimento do segmento turístico relacionado ao vinho, autores como Charters e Ali-Knight (2002) sugeriram que se estudasse o perfil dos frequentadores de espaços onde a apreciação do vinho era a principal atração. Ainda segundo os autores, estas análises eram baseadas, principalmente, na motivação que levavam os amantes da bebida a frequentar esses lugares, além do conhecimento e do interesse a respeito do vinho e das atividades envolvidas.

Enobares, por exemplo, são espaços do meio urbano que oferecem como atrativo principal o vinho. A socialização entre os frequentadores é o segundo aspecto, 
configurando-se como um ambiente favorável para quem deseja degustar, conhecer e saber mais sobre esta bebida.

Neste sentido, identifica-se a importância que o tema apresenta nesta nova realidade brasileira que, gradativamente, vem fazendo parte da concorrência mundial na produção e comercialização de vinhos. Além disso, ter como plano de fundo a cidade de São Paulo significa tratar do maior destino turístico do país que conta com superlativa oferta de lazer formada, por exemplo, pelos 12,5 mil restaurantes e 15 mil bares (SÃO PAULO, 2011).

Assim, estabeleceu-se como objetivo central da pesquisa mapear os enobares da cidade de São Paulo, analisando a localização e a distribuição destes pela cidade por meio de recurso da web (Google Maps). Também, a partir da seleção de cinco estabelecimentos, buscou-se identificar o perfil dos consumidores/frequentadores destes locais, por verificação da frequência, faixa etária, gênero e principais atividades realizadas pelos consumidores na temática abordada, além da averiguação do grau de conhecimento sobre a bebida, a fim de categorizá-los em quatro perfis: apreciador, interessado, frequentador casual e acompanhante.

Este estudo apresenta um modelo de como analisar estes consumidores, ressaltando sua relevância no atual contexto brasileiro. Ao mesmo tempo, justifica-se academicamente pela inovação da análise com foco no cliente, a qual contribui para uma abordagem econômico-mercadológica e, também, psicológica. Dessa forma, colabora com o planejamento e estimula o desenvolvimento da indústria de vinhos, além de destacar o indivíduo como sujeito dotado de anseios, necessidades, desejos e prazeres a serem atendidos e entendidos.

\section{BINÔMIO: O ENOTURISMO E O ENOTURISTA}

O turismo, no contexto atual, apresenta-se como objeto de estudo que contribui para uma visão interdisciplinar e, ao mesmo tempo, apurada. Além de fenômeno que suscita alterações na sociedade, permite o destaque das particularidades sociais e os fluxos dela consequentes, por meio do intercâmbio de costumes, informações, pessoas e/ou tradições (PANOSSO NETTO, 2010). 
Diante destas características, para a pesquisa se analisa o turismo como proporcionador de novas vivências, fenômeno global e influente nas diversas práticas sociais.

O crescimento deste fenômeno devido, dentre outros fatores, ao desenvolvimento da mobilidade urbana, dos transportes e da tecnologia contribuiu, também, para o surgimento de novos segmentos turísticos (BRASIL, 2013). Um exemplo destes é o enoturismo.

Embora existam indícios históricos de que a busca pela apreciação do vinho e de visitas e viagens às regiões vitivinícolas (regiões onde há produção de uvas e vinhos) eram encontradas nas civilizações gregas e romanas e que estas práticas tenham sido passadas por séculos até os dias atuais (COSTA, 2008), o conceito de enoturismo somente apareceu após a Segunda Guerra Mundial (BRAMBILLA, 2010).

Contudo, foram nos últimos quarenta anos que este setor progrediu conquistando o Leste Europeu que, posteriormente, passou a ter por objetivo atrair o Oeste da Europa (TONINI, 2007). Diante da crescente comercialização do vinho, novos mercados emergiram desenvolvendo rotas enoturísticas (HALL et al, 2004), como é o caso da Austrália, Nova Zelândia, Estados Unidos da América, Canadá, África do Sul e alguns países latinos americanos (JOHNSON, 1989).

Esta propagação exigiu uma série de afazeres e deveres dos produtores de vinho e pesquisadores para tornar a vitivinícola atrativa para o público-alvo deste mercado, de modo que houvesse uma interação não só entre vinho e turismo, mas também entre a produção e apreciação deste produto e o próprio turista.

Com o intuito de entender a motivação do viajante em conhecer uma região produtora de vinho, pesquisas vêm sendo realizadas a fim de investigar quais aspectos chaves incentivam a experienciação deste tipo de local. Enquanto alguns autores apontam que o vinho é elemento exclusivo para a realização deste segmento turístico, como é o caso de Dott e Bigotte (1997), Getz (1999) identifica que a busca por espaços abertos que promovam o contato com a natureza e belos cenários são algumas características que estimulam este perfil de turista. Hall et al. (2004) destaca outros três elementos, o vinhedo, as adegas e o processo de vinificação, como atrativos de grande potencial. 
De forma a combinar os três estudos mencionados, Hall e Mitchell (2002) afirmam que não apenas os aspectos físicos, mas também a combinação singular dos aspectos culturais, naturais e ambientais presentes, diferenciam cada região e sensibilizam o turista a conhecer rotas enoturísticas.

Por conta disso, pesquisas começaram a ser realizadas para melhorar e ampliar este setor de maneira sustentável.

Assim, pesquisadores como Charters e Ali-Knight (2002), verificam a relevância de estudar também o turista neste cenário, isto é, o enoturista, frequentador de regiões vitivinícolas, interessado em desfrutar dos prazeres do vinho e em conhecer a produção e a cultura de um determinado local.

Ainda segundo Charters e Ali-Knight (2002) o conhecimento desses sujeitos, propagadores das novidades do ramo, ajuda a fomentar a indústria de vinhos, colabora com o planejamento, o desenvolvimento dessas regiões e intensifica o turismo bem como proporciona benefícios que vão além dos lucros.

Em estudo realizado na Austrália, Charters e Ali-Knight (2002) especificam quatro categorias de enoturistas conforme a motivação: amantes do vinho, na qual o principal objetivo do turista é aprimorar seu conhecimento e desvendar o estilo de vida do local; interessados pelo vinho, onde a motivação é degustar e aprender sobre o vinho sem se importar com a cultura local; amadores de vinho, os quais se interessam pelo vinho quando a localidade visitada está próxima de cantinas e vinhedos; penetras, que não possuem interesse sobre o vinho e que apenas participam, pois são acompanhantes de alguém ou de algum grupo.

\section{CULTIVO E CONSUMO DO VINHO PELOS BRASILEIROS}

O consumo de vinhos pela população brasileira ainda apresenta valores modestos se comparados ao consumo de outros países com uma cultura mais acostumada a apreciação da bebida, como é o caso dos franceses e italianos (INSTITUTO DA VINHA E DO VINHO, 2012). Contudo, a cada ano estes valores aumentam, resultado da apropriação das novas tecnologias para o desenvolvimento de vinhos em diversas regiões brasileiras, assim como a flexibilização das taxas nas 
importações nacionais permitindo aos consumidores maior acesso ao produto (VINHOS DO BRASIL, 2013).

O Brasil é um país de grandes dimensões e é possível encontrar variados climas e condições ambientais em seu território. Essa variedade influencia diretamente a produção de vinhos nas regiões do país, trazendo diferenças na elaboração de cada produto (IBRAVIN, 2013, online).

A viticultura de clima temperado está concentrada nos estados das regiões Sul e Sudeste e representa $88 \%$ das áreas de vinhedos no país, destacando-se nesta área a Campanha e Serra do Sudeste, localizadas na metade sul do Rio Grande do Sul; a Serra Gaúcha, localizada no noroeste do mesmo estado; a região do Vale do Rio do Peixe no Estado de Santa Catarina, assim como sua região sul; e na região leste do Estado de São Paulo e sul de Minas Gerais (IBRAVIN, 2013, online).

Respondendo por mais de $85 \%$ da produção nacional de vinhos, a região sul é caracterizada como a maior e mais importante "região vinícola" do Brasil, fato este decorrente, dentre outro fatores, da chegada dos italianos no local que criaram as primeiras estruturas para o desenvolvimento da indústria no país (IBRAVIN, 2013, online). As condições específicas de clima ali presentes proporcionaram o cultivo de uvas com uma personalidade mais forte e singular (VINHOS DO BRASIL, 2013).

Em relação à viticultura subtropical, a região a ser destacada é a do Norte do Estado do Paraná visto que, como símbolo da cultura local, o cultivo da uva é fator representante da economia paranaense e, atualmente, estende seu potencial através de roteiros enoturísticos em toda região (VINHOS DO BRASIL, 2013).

A viticultura tropical possui como destaque as regiões noroeste de São Paulo, norte de Minas Gerais e o Vale do Sub-médio São Francisco com vinhedos nos Estados de Pernambuco e Bahia (IBRAVIN, 2013, online).

Já em São Paulo, a produção ocorre em duas regiões, Noroeste e Leste, principalmente nas cidades de Jales, Jundiaí, Vinhedo, Indaiatuba, Valinhos, Campinas, Sorocaba, Itapetininga e São Miguel Arcanjo, sendo que os principais tipos de uvas cultivadas são Uvas Finas e Uvas Americanas (IBRAVIN, 2013, online).

Na totalidade, o cultivo de uva no Brasil ocupa uma área de aproximadamente 92 mil hectares espalhados pelo país desde regiões no extremo sul até áreas mais ao norte, produzindo cerca de 3.450 mil hectolitros de vinho no ano de 2011 (INSTITUTO 
DA VINHA E DO VINHO, 2012). Atualmente, são mais de 1,1 mil vinícolas espalhadas pelo país, em geral propriedades de pequeno porte que ocupam, em média, 2 hectares por família (VINHOS DO BRASIL, 2013, online).

Uma pesquisa realizada pela Wine Intelligence em 2012 sobre o consumo de vinhos importados pelos brasileiros mostrou que a população do Estado de São Paulo consome cerca de 50\% destes vinhos. Ademais, a renda dos consumidores, que bebem ao menos duas vezes por ano este tipo de vinho, é, em média, superior a $\mathrm{R} \$ 2.000$, sendo que apenas $2 \%$ afirmam apreciar a bebida todos os dias. Vale ressaltar também, que o vinho tinto é o de maior consumo entre os respondentes (94\%), seguido do vinho branco $(65 \%)$ e espumante (36\%) (WINE INTELLIGENCE, 2013).

Em relação aos vinhos nacionais, as vendas em 2011 somaram 19,5 milhões de litros comercializados, movimentando mais de $\mathrm{R} \$ 1,2$ bilhão, sendo as garrafas mais vendidas, aquelas que custam em torno de $\mathrm{R} \$ 30$ e $\mathrm{R} \$ 50$ (CASTRO, 2013, online).

Segundo a IBRAVIN (2013, online), no primeiro semestre de 2013, o mercado interno brasileiro de vinhos registrou incremento sutil de $2,54 \%$, se comparado ao mesmo período do ano anterior, na comercialização de vinhos finos, de mesa e espumantes, o que totalizou 107,9 milhões de litros.

Até 2016, espera-se que o consumo da bebida no país cresça 30\%, ampliando para 2,5 litros per capita (e, em regiões de maior consumo, como Sul e Sudeste, 20 litros por ano) e aumentando as vendas para 40 milhões de litros, representando "a ampliação para $25 \%$ da presença de vinhos finos brasileiros nos supermercados" (CASTRO, 2013, online).

\section{CONTEXTUALIZAÇÃO SOBRE O TEMA DOS ENOBARES}

Até onde foi possível a investigação, verificou-se a ausência de estudos a respeito especificamente dos enobares, o que suscitou a análise primeira dos espaços em que a bebida alcoólica era o principal atrativo. São exemplos destes primeiros espaços as tabernas e pubs a serem abordados a seguir.

Diante do caráter singular que o vinho ganhou ao longo dos anos, mostrou-se oportuna a criação de estabelecimentos especializados para o consumo da bebida. Desde 
os primeiros povos da antiguidade, estes locais tinham como principal atração o vinho e a sociabilidade, sendo, neste período, frequentados especialmente pelo público masculino (BUSSOLABAR, 2013, online).

Os registros históricos do primeiro milênio mostram que na Mesopotâmia, particularmente onde habitava o povo sumério, este tipo de local já existia, contudo, a bebida que mais se consumia era a cerveja e em culto à deusa Inanna, deusa do amor, da fertilidade e da guerra (LEICK, 2003).

No entanto, é ainda no período da antiguidade, que o vinho passa a ser a bebida mais consumida e vendida nas tabernas (ou tavernas) gregas e romanas, estabelecimentos estes que ofereciam, além do vinho, comida, pouso e diversão (LEICK, 2003).

No período de dominação do Império Romano, estes estabelecimentos também eram conhecidos como popina, caupona e bodega, e constituíam-se numa grande cozinha e sala para recepcionar os clientes que se acomodavam em mesas ali distribuídas para o consumo da bebida e comida simples (CAMPOS, 2013).

De acordo com Tonini (2007), os romanos passaram a se dedicar a vitivinicultura, pois esta atividade estava se tornando uma atividade rentável naquele período, além disso, era uma forma de se venerar e festejar o Deus do Vinho romano, Baco.

Segundo Campos (2013, p. 16), "no interior da taberna, sob a luz bruxuleante de tochas, com canecas a trasbordar de vinho, sidra e cerveja e música alegre todos voltamse para aquele que fez do suco fermentado da vinha o grande alento para as dores do corpo e de alma". Apesar de desfrutarem de situações diferentes, jogando, bebendo ou "entregando-se aos prazeres carnais", todos os que estavam ali serviam a Baco (CAMPOS, 2013, p. 16).

No entanto, com a queda do Império Romano por volta do século IV d. C., a produção vinícola foi interrompida, sendo retomada pela Igreja Católica apenas no período da Idade Média, quando o vinho passou a ter um significado litúrgico e, portanto, sagrado (TONINI, 2007).

Ademais, Campos (2013) complementa que é a partir deste momento que as tavernas passam a ser reconhecidas como lugar para malfeitores, ladrões e prostitutas, principalmente pelo fato de se localizarem em regiões mais pobres. Esta imagem irá se 
estender para além da Idade Média, evidenciando que nobres e abastados eram proibidos de frequentar estes espaços, porque iam contra as leis de hospitalidade.

Ainda sobre o período medieval é fundamental destacar que as tabernas localizadas nas estradas foram importantes para o desenvolvimento de alguns núcleos urbanos, pela prosperidade do comércio e por serem identificadas como os primeiros locais sinônimos dos hotéis (CAMPOS, 2013).

Com a modernidade e o grande desenvolvimento das cidades, pautou-se a necessidade de se criarem novos espaços para atender a população crescente, principalmente no que diz respeito à alimentação e ao lazer, o que garantiu espaço para ampliação do número das tavernas na Europa e, inclusive, no Brasil (ALGRANTI, 2011).

O Brasil do período colonial também possuía suas tabernas e botequins que comercializavam a bebida alcoólica, em particular a aguardente para consumo no local, e, com a chegada da corte em 1808 no Rio de Janeiro, as condições para venda, bem como o aumento da procura por produtos importados foram facilitadas, destacando-se a venda de artigos de luxo e bebidas estrangeiras (ALGRANTI, 2011).

João Ignácio da Cunha, intendente em 1821, escreveu num ofício que nas tabernas e armazéns da cidade (ALGRANTI, 2011, p. 31):

[...] de dia e noite se juntava grande porção de pretos por consentimento dos taberneiros pelo lucro que percebem na venda de aguardentes e mais gêneros e dali se retiram a fazerem desordens pela cidade e mesmo à porta das tabernas com ofensas à segurança pública, a que a polícia deve acudir para evitar males e não serem molestados os povos

Diante desta situação, não só no Brasil, mas também na Europa, houve a tentativa de regulamentar o funcionamento das tabernas que eram vistas pelas autoridades locais como foco de instabilidade da ordem pública, perversão e ameaça à moral social (RODRIGUES, 2012).

Assim, a taberna é reconhecida por sua importância como atividade econômica rentável, caracterizando-se como grande negócio para os produtores de uma localidade e despertando outros produtores para o desenvolvimento do seu próprio negócio, por meio da comercialização da bebida alcoólica em suas próprias adegas, vendas ou mercearias (RODRIGUES, 2012). 
Pode-se afirmar que, apesar da longa trajetória das tabernas, atualmente elas apresentam uma configuração parecida com a de sua origem, mantendo as características funcionais, sendo a bebida o principal atrativo, mas também em termos de espaço, isto é, figurando-se em dimensões variáveis, arquitetura simples com preocupações mínimas na decoração e sendo, muitas vezes, associadas a uma adega ou venda de vinho.

Quanto à funcionalidade citada, esta também abrange outros fatores nos quais:

[...] a taberna é muito mais que o "lugar de perdição" destinado ao consumo de bebidas alcoólicas.

A taberna é também um local de encontro e de convívio, onde o petisco serve de pretexto ao consumo do vinho em grupo, e envolto numa série de rituais desenvolvidos com grande à-vontade pelo frequentador habitual destes espaços. É igualmente um local privilegiado para a manifestação da cultura popular, da opinião e da manifestação contra-poder (RODRIGUES, 2012, p. 5 , grifo do autor).

Contudo, o mesmo autor afirma que o futuro deste espaço está em risco, uma vez que hoje, os laços de sociabilidades que eram ali estabelecidos e a rotina de se frequentar tabernas, já não acontecem mais.

Em relação a isso, pode-se afirmar que as tabernas estão perdendo lugar para novos espaços de sociabilização, mas que, em princípio, são bastante similares a estes estabelecimentos. É o caso dos bares, pubs e seus decorrentes.

A respeito da origem do nome bar, acredita-se que, na França, por volta do século XVIII, as tavernas passaram a instalar barras (barre em francês e bar em inglês; em espanhol o termo 'barra' é usado para designar o balcão do bar) para protegerem os balcões, ideia esta que se universalizou e popularizou-se, nomeando todos os locais que havia a venda de bebidas alcoólicas como bares (CLUBEER, 2013, online).

Já os Pubs, de origem inglesa, receberam este nome por representarem casas públicas, ou seja, eram (e são) espaços para a reunião de amigos, da mesma forma que as tabernas. Dentre outras semelhanças, citam-se as paredes rústicas feitas de madeira, mesas com bancos altos, ambientes de pouca iluminação, e as várias opções de bebidas alcoólicas (CLUBEER, 2013, online).

Assim, "o bar pode ser espaço de celebração, comemoração, consumo, paquera, mas é, sobretudo, um lugar onde o lúdico se desenvolve. O riso, em suas mais variadas 
formas, é vivido e representado em torno das mesas, da bebida, do encontro" (BARRAL, 2006, p. 99).

A partir destas características e toda história descrita, pode-se considerar que o enobar se estabelece como espaço que integra o significativo estímulo pela apreciação do vinho presente nas tabernas, com a oportunidade de sociabilização, prática do lúdico, e vivência do divertimento, descanso e desenvolvimento do lazer explicitado nos bares atuais.

Por seu caráter versátil, estimulam a cultura do vinho, contribuem para o crescimento deste mercado no Brasil, oferecem um espaço para aprendizado da cultura vinícola, harmonizações e degustações, tornando este conhecimento simplificado e acessível.

A respeito destas novas ramificações, menciona-se Magalhães (2001, p. 2, grifo do autor) que através de estudos, notou que:

\begin{abstract}
[...] dada as exigências da vida moderna, vai se tornando habitual assistir-se à re-estruturação de espaços na taberna, multiplicando-se as suas lógicas de vivência subjacentes, não raro, à concorrência comercial. [...] fica no entanto patente alguma diferença quer entre tipos de estabelecimentos que, tentando adequar-se às novas exigências de vida moderna, viram os seus espaços reestruturados, ampliados e/ou reaproveitados e aos quais não era ou passou a não ser alheio o fornecimento de refeições - [...] referimo-nos aos estabelecimentos que funcionam essencialmente na lógica tabernal, isto é , com o balcão. [...] Os petiscos, as sandes, as pataniscas e os salgados em geral são o seu prato forte.
\end{abstract}

Tais características fazem do enobar exemplo deste espaço reestruturado em que se procura adequar à vida contemporânea nos modelos "tabernais". Como aspectos similares citados por Rodrigues (2012), também está presente nos enobares o petisco como "pretexto para o convívio à mesa e para o consumo do vinho"; o mobiliário buscando a funcionalidade do espaço; artesanatos que marcam presença e fazem referência à madeira, cortiça, rolhas, taças e garrafas de vinhos.

Porém, se anteriormente havia pouca preocupação com a decoração do local, o que se percebe atualmente são espaços cada vez mais inovadores e arrojados, que mantém a característica rústica, mas exploram elementos requintados e distintos. O público feminino se faz presente e procura conhecer e se aprofundar sobre o mundo dos vinhos (RODRIGUES, 2012). 


\section{METODOLOGIA}

Na presente pesquisa optou-se pelo uso da abordagem qualitativa para embasar o estudo e atingir os objetivos propostos, visto não ser possível mensurar as questões substantivas que os envolvem. A abordagem qualitativa da pesquisa se explica pelo fato de que perante a realidade complexa e emergente que se observa "é preciso procurar pesquisar também suas faces qualitativas" (DEMO, 2000, p. 145).

Num primeiro momento, realizou-se a pesquisa bibliográfica por meio da qual foram analisados materiais bibliográficos pertinentes, tais como livros, artigos científicos, monografias e sites para o levantamento teórico do projeto, que trouxessem um breve histórico e os principais conceitos da temática para embasar o estudo.

Em seguida, desenvolveu-se o inventário de enobares, utilizando recursos da Web (Google Maps) de modo a obter dados como localização e informações adicionais acerca dos enobares da cidade de São Paulo.

Esta etapa teve como objetivo levantar e mapear todos os enobares da cidade de São Paulo para que, a partir deles, se pudesse identificar o perfil de seus frequentadores e atender os objetivos específicos propostos.

Por conveniência, selecionaram-se cinco para a realização da aplicação dos questionários: Divine Wine Bar, Tendai Sushi \& Wine, Casa do Porto, Enoteca Decanter e La Madrileña, sendo que os dois primeiros foram selecionados para a realização do pré-teste.

Por meio da análise da bibliografia existente, constatou-se ser necessário perfilar quem eram os frequentadores dos enobares da cidade de São Paulo para atingir os objetivos específicos da pesquisa. Como argumentam Charters e Ali-Knight (2002, p. 311):

Há dois processos de análise e segmentação de enoturistas enquanto mercado potencial. O primeiro é de categorização do cliente - ao lidar com a demografia de modo a estabelecer sua proveniência, como idade e educação, e os antecedentes familiares. A segunda questão é perfilar - detalhar sua base psicográfica - seus valores, atitudes e modos de vida.

Para tal, optou-se pela utilização de questionários que segundo Martins e Teóphilo (2007, p. 90) são um "conjunto ordenado e consistente de perguntas a respeito de variáveis e situações que se deseja medir ou descrever". Tais questionários eram 
compostos de questões fechadas cuja coleta de dados buscou analisar o perfil dos frequentadores dos enobares a fim de categorizá-los.

As perguntas formuladas referiam-se ao nível de interesse, à autoclassificação do conhecimento sobre o vinho, à realização de atividades relacionadas à bebida nos últimos doze meses e/ou futuras, à frequência e às principais motivações a visitas aos enobares e à posse de adega climatizada na moradia.

Após a elaboração do questionário, estes foram aplicados em dois dos cinco enobares escolhidos para amostragem, caracterizando-se o pré-teste, cujo objetivo era o de verificar suas possíveis falhas, inconsistências e ambiguidades para que fosse aperfeiçoado (MARTINS; THEÓPHILO, 2007). Este foi executado no dia 30 de maio de 2013.

Realizadas as adaptações necessárias, foram aplicados os questionários oficiais: no dia 31 de maio (sexta-feira) no Divine Wine Bar, Casa do Porto e Tendai Sushi \& Wine, entre $19 \mathrm{~h}$ e $2 \mathrm{~h}$; dia $1^{\circ}$ de junho (sábado) no La Madrilenã e 4 de junho na Enoteca Decanter, das 18 às $22 \mathrm{~h}$.

Em seguida, passou-se a uma análise interpretativa do conteúdo das respostas. Desse modo, categorizaram-se os frequentadores dos enobares, de acordo com suas motivações, em: apreciador, interessado, frequentador casual e acompanhante.

Esta proposta é baseada na classificação dos enoturistas segundo Charters e AliKnight (2002), que avaliaram as principais motivações deste público para a realização do enoturismo (amantes do vinho, interessados pelo vinho, amadores do vinho e/ou penetras). Tais autores afirmam que "a classificação de enoturistas com base em seu interesse por vinho é considerada um possível método para segmentá-los" (CHARTERS; ALI-KNIGHT, 2002, p. 315).

\subsection{MAPEAMENTO E DISCUSSÃO DOS ENOBARES}

A fim de se verificar a distribuição dos enobares na cidade de São Paulo, optouse pela utilização de recursos da web (Google Maps), identificando 32 enobares na capital (ver apêndice A).

Verificou-se que destes 32, 22 se apresentavam na zona sul de São Paulo, seguidos de 7 na zona oeste, 1 na zona leste, 2 no centro e nenhum na região norte. Rodeados por avenidas de grande movimento da cidade (Avenidas 23 de Maio, 
Rebouças, Nações Unidas e dos Bandeirantes) garantindo o fluxo contínuo de um público diverso em preferências e estilos.

Percebeu-se que os enobares se localizavam em regiões consideradas nobres da capital paulista, com maior concentração na zona sul da cidade, em especial nos bairros Itaim Bibi e Jardim Paulista, fato este que restringe a circulação de pessoas de condições financeiras inferiores ao padrão local.

Esta circunstância perpassa outras condições que, direta ou indiretamente, foram encontradas nas respostas dos questionários. Como exemplo disto, a grande maioria dos respondentes mencionou já terem participado de viagens enoturísticas, segmento este bastante valorizado no mercado atual e que indica um público que já conhece e é familiarizado com a bebida.

Além disso, tem-se a questão do custo do vinho. O consumo mesmo que baixo na cidade de São Paulo ainda é restrito a uma população de renda média superior a $\mathrm{R} \$$ 2.000,00, população esta que corresponde a $24 \%$ dos brasileiros (INDICADOR BRASIL, 2012). Assim, tem-se que o público que estava frequentando os enobares do recorte apresentado é bastante elitizado, visto que os equipamentos, de modo geral, atendem a população do seu entorno.

A partir destas variáveis e das respostas obtidas com a pesquisa de campo, foram criadas quatro categorias para classificar os frequentadores de enobares, que são apresentadas a seguir.

\subsection{APRECIADORES}

Os entrevistados que se encaixaram na categoria de "apreciadores" são aqueles que, com base nas respostas fornecidas nos questionários, apresentaram os maiores índices de interesse e conhecimento sobre vinho, assim como grandes índices de participação em atividades relacionadas à bebida.

Dentre os entrevistados que se enquadraram nesta categoria foi possível perceber uma predominância de pessoas na faixa de idade entre 30 e 40 anos. Além disso, o número de homens apreciadores na amostra foi proporcionalmente maior que o de mulheres, o que pode ser entendido como um reflexo do fato de a maioria dos frequentadores dos enobares ser do público masculino. Em relação ao nível de interesse pela bebida, todos os apreciadores apresentaram o nível máximo de interesse na bebida, 
ou seja, 5 em uma escala de 0 a 5 (considerando-se que 0 é nenhum interesse e 5 totalmente interessado).

O público feminino se classificou predominantemente como conhecedoras do vinho e, dentre as atividades que estas realizavam com frequência ou realizaram nos últimos 12 meses, se destacaram a ida aos enobares, palestras, degustações da bebida, a realização de atividade enoturística, assim como a visitação de websites especializados no assunto.

Indo ao encontro do público feminino, os homens da categoria também praticavam predominantemente atividades como enoturismo, frequentação a enobares, degustações, palestras e visitas a sites, entretanto, em relação ao nível de conhecimento, as respostas variaram entre conhecedores e grande conhecedores.

Sobre o interesse que os entrevistados possuíam pela prática de atividades relacionadas ao vinho no futuro, percebeu-se que pelo fato de a maioria deles já praticarem muitas das atividades listadas na questão anterior e pela maneira como a pergunta foi formulada, não houve nenhuma atividade que se destacou em nenhum dos públicos.

A totalidade dos entrevistados nesta categoria frequentou enobares mais de quatro vezes no ano anterior e, além de todos possuírem o vinho como uma das principais motivações, as demais categorias como a interação social, relaxamento e até mesmo pela comida servida nos estabelecimentos, apareceram frequentemente. Percebeu-se assim, que mesmo o vinho sendo o "carro-chefe" dos enobares, outros aspectos também se fizeram importantes para os seus frequentadores, que o perceberam como um espaço não apenas para aproveitar a bebida, mas também como um ambiente de socialização que proporciona tranquilidade e momentos de lazer.

Outro importante aspecto observado é que a grande maioria dos entrevistados desta categoria comentou possuir adega climatizada em suas residências, aspecto este singular e que afirma a importância que o vinho possuía em suas rotinas.

\subsection{INTERESSADOS}

Outra categoria sugerida e investigada por este estudo foi a dos interessados, ou seja, pessoas que possuem um grande nível de interesse pelo vinho, frequentam enobares, especialmente pela bebida, possuem um conhecimento satisfatório sobre 
vinhos além de praticar pelo menos duas atividades relacionadas. Além disso, estão interessados em vivenciar novas experiências.

O público masculino deste grupo apresentou idade entre 31 e 40 anos, possuindo altíssimo interesse em vinho e se considerando conhecedor ou conhecedor limitado. Eles alegaram que frequentavam os enobares mais de quatros vezes por ano em virtude da comida, do relaxamento, do descanso, da socialização, porém sendo a bebida a principal razão.

As atividades mais realizadas mencionadas foram: frequentar enobares, participar de degustação, visitar sites específicos além do enoturismo, que também apareceu em destaque. Quanto às possíveis atividades futuras, as mais apontadas foram: enoturismo e degustação. Outras também evidenciadas foram a de ser um sócio de clube e de fazer parte de confrarias.

Já o público feminino desta categoria foi mais jovem, entre 21 e 30 anos. Possuindo alto interesse sobre vinhos, porém classificando seu conhecimento como limitado. Assim como o público masculino, afirmaram que sua frequência aos enobares era maior que quatro vezes ao ano, contudo para elas a bebida era, unanimemente, a principal motivação.

Dentre as atividades predominantemente realizadas por este grupo teve-se as visitas aos enobares e sites específicos, assim como a participação em degustações. Em meio as eventuais atividades, a mais destacada foi a de enoturismo seguida por participação em confrarias e aquisição de publicações especializadas. Quanto à adega climatizada a maioria dos entrevistados nos dois públicos mencionou não a possuir.

O enoturismo, apontado como a atividade futura mais escolhida, foi de mesma relevância nos dois gêneros. Notadamente, este setor permite o aprofundamento no conhecimento da cultura, história e da gastronomia local, através de experiências singulares que diferenciam este segmento de público do dos apreciadores do vinho.

\subsection{CASUAL}

$\mathrm{Na}$ análise da categoria "Casual" foram 17 entrevistados no total, sendo a maioria do sexo masculino (11). Notou-se que todos os entrevistados possuíam mais de 20 anos de idade, sendo que a maior parte do público total concentrava-se na faixa etária de 21 a 30 anos de idade. No público masculino obtiveram-se entrevistados até na faixa 
dos 61 a 70 anos de idade, diferente do público feminino em que a faixa etária foi entre 41 e 50 anos de idade.

Com relação ao nível de interesse, na escala de 1 a 5 , a maior parte dos entrevistados disse possuir nível 3 e se considerar conhecedor limitado.

Dentre as atividades realizadas, a maior parte dos entrevistados frequentava enobares. Destacou-se a realização de degustações por parte do público masculino e a ida a palestras, feiras, exposições, cursos no público feminino. Tanto enoturismo como leilões e participações de confrarias foram constatados como atividades não realizadas por este nicho.

Mais uma vez o enoturismo foi ressaltado como a principal atividade futura para a maior parte dos casuais. As degustações também foram o destaque no público feminino e a ida a palestras, feiras, exposições e cursos no público masculino.

Com relação à frequência de visita aos enobares (nos últimos 12 meses), tanto os homens como as mulheres destacaram ir mais de quatro vezes. Apenas 2 entrevistados declararam ser a primeira vez que visitavam.

A motivação principal do público, como já esperado, foi a bebida. Como segundo fator principal, a comida foi o destaque para ambos os públicos. Já o socializar foi maior para o público masculino enquanto que o relaxar foi o que se destacou no público feminino.

Vale ressaltar que apenas 1 entrevistado declarou possuir adega climatizada.

\subsection{ACOMPANHANTES}

Outra categoria plausível de se amoldar esses frequentadores de enobares foi denominada "acompanhantes". O principal aspecto de sua existência é a visita a enobares que não impulsionada pelo consumo do vinho, mas por outros aspectos como socializar, acompanhar alguém, relaxar e desestressar.

É esta categoria de frequentadores de enobares análoga aos enoturistas penetras apontados por Charters e Ali-Knight (2002), os quais não possuem interesse sobre o vinho e que apenas participam, pois são acompanhantes de alguém ou de algum grupo.

No que tange sua idade, o público masculino tinha, em sua maioria, entre 30 e 40 anos, enquanto que o feminino, entre 40 e 50 anos. 
Como características principais de tal categoria obtiveram-se a presença de quaisquer níveis de interesse, níveis de conhecimento, números de atividades praticadas, números de interesse em atividades futuras e qualquer frequência de visita. Além de não possuírem a bebida como principal motivação da visita aos enobares.

Em tal categoria, observou-se uma predominância do público masculino em detrimento do feminino, o que refutou a hipótese de que as mulheres seriam maioria nessa análise, por acompanharem seus/suas parceiros/as na visita ao enobar. Por outro, lado pode-se explicar essa situação pelo fato de o público masculino entrevistado ser em maior quantidade que o feminino.

No entanto, como aponta Barral (2006) ao analisar os pubs, nos dias de hoje estes locais se destacam como atrativos para o público jovem, tanto masculino quanto feminino, isto é, um espaço heterogêneo, no qual a conversa e a bebida tornam-se as principais atividades de lazer desenvolvidas, assim como ocorre nos enobares.

Em relação ao nível de interesse dos entrevistados, encontraram-se números altos - maioria masculina com nível 5 de interesse e feminina com níveis 3 e 5 -, enquanto que, em relação ao conhecimento, o público masculino apontou conhecimento limitado e o feminino, conhecimento limitado ou ser conhecedor. Inferiu-se que, devido a este pouco conhecimento, na verdade, o acompanhante passa a desenvolver interesse em conhecer mais sobre o vinho, por conta de seu par frequentar os enobares.

Dentre as atividades praticadas por esse segmento de público analisado, ressaltase a frequência a enobares, a participação em degustações e palestras e a visitação de sites especializados em vinhos. Assim, aponta-se que a degustação é uma primeira forma de contato com o vinho e a mais fácil de mantê-lo, uma vez que não é necessária a compra de uma ou mais garrafas para que a atividade seja praticada. Sobre as atividades que se pretendia fazer, observou-se a prática do enoturismo, das degustações e da continuação de visita a enobares.

Quanto a essa visitação a enobares, sua frequência mostrou-se elevada: tanto o público masculino quanto o feminino, em sua maioria, haviam ido a enobares mais de quatro vezes nos doze meses que antecederam a pesquisa. Tal fato confirmou a constatação de que o consumo de vinhos pela população brasileira ainda apresenta valores modestos se comparados ao consumo de outros países com uma cultura mais acostumada a apreciação da bebida, como é o caso dos franceses e italianos. 
Outro aspecto que divergiu do esperado foi o fato de os entrevistados possuírem adega climatizada em suas residências. O número foi elevado: 7 dos 11 homens entrevistados a possuíam. No caso feminino houve uma diferença; apenas uma das cinco a tinha. Sendo as pessoas que se enquadraram nesta categoria apenas aquelas que acompanham um par, é possível apontar que é esse par interessado e conhecedor de atividades relacionadas a vinho que possui uma adega, que acaba por ser compartilhada com aquele que o acompanha.

\subsection{ABORDAGEM GERAL}

Através da aplicação dos sessenta questionários nos diferentes enobares localizados na região selecionada para estudo, foi possível obter a visão quanto aos perfis dos frequentadores destes ambientes, examinados nos subtópicos anteriores (ver apêndice B). Deste modo, certas características se mostraram comuns entre os consumidores possibilitando o levantamento de algumas conclusões sobre este nicho de mercado.

A primeira foi com relação à idade dos frequentadores, quando se constatou que a maior parte se concentrava na faixa etária dos 30 até os 50 anos de idade. Além disso, em todos os perfis analisados foi perceptível a predominância do público masculino.

Apesar de a maioria possuir nível de interesse 5, obteve-se em destaque o conhecimento mediano a respeito dos vinhos. Assim, verificou-se que muitas pessoas demonstraram possuir interesse em aprender mais a respeito disto, entretanto este anseio não era tão elevado a ponto de fazê-las se aprofundar no assunto, buscando se envolver em atividades paralelas que incentivassem o "descobrimento do mundo dos vinhos".

Mais de trinta dos sessenta entrevistados indicaram a degustação como atividade realizada frequentemente, e, logo em seguida, apareceram as visitas a sites especializados, demonstrando que além das degustações, as pessoas tentavam obter informações utilizando meios de comunicação de fácil acesso e baixo custo. Dentre as atividades futuras, teve-se destaque o enoturismo.

Ressalta-se que, quanto à frequência aos enobares, independente do perfil em que se encontrava, a maioria dos entrevistados mencionou comparecer mais de quatro vezes durante o ano. Isso demonstrou que o enobar é um estabelecimento de convívio e interação social, mas, principalmente, um espaço para aproximação e apreciação da 
bebida. Esta situação ficou evidenciada quando se analisa a motivação, em que, após a bebida, gastronomia e socializar foram os principais fatores que levaram as pessoas a visitarem enobares.

Também é válido mencionar que na categoria dos acompanhantes outras motivações foram citadas, como por exemplo, o enobar como um espaço de lazer, para fazer compras e conhecer pessoas.

Pôde-se concluir que os perfis estabelecidos na pesquisa podem corresponder a uma escala de envolvimento e conhecimento do mundo dos vinhos. Primeiramente, as pessoas iniciam-se como acompanhantes por meio de indicações/ou convites de amigos. Após estes contatos inaugurais, procuram conhecer sobre o assunto, tendo suas vivências em degustações e frequência nos estabelecimentos, passando de acompanhantes para casuais. Tornam-se interessados quando o consumo de vinho configura-se algo mais corriqueiro, bem como a prática de outras atividades, podendo até mesmo opinar sobre o assunto. $\mathrm{O}$ apreciador é aquele que considera a bebida parte do seu cotidiano e faz dela "objeto" singular; conhece suas particularidades, desenvolvimento e "etiquetas de apreciação", valorizando-a de tal modo que possuem suas próprias coleções e adegas.

Portanto, na presente realidade brasileira tal evolução demonstra um mercado emergente e crescente que pode tornar-se competitivo, contribuindo, não apenas economicamente, mas também cientifica e academicamente, uma vez que suscita novas pesquisas tanto para melhor compreensão da bebida e suas consequências, quanto do próprio indivíduo que a consome e promove novas atividades para sua experimentação.

\section{CONSIDERAÇÕES FINAIS}

Tem-se o vinho como um elemento fundamental para compreensão do cotidiano da sociedade e de seus espaços e relações sociais, uma vez que este sempre esteve presente na realidade dos povos antigos até a sociedade atual. Mesmo com sua valorização mercadológica, este continua sendo símbolo de refino e prazer e que proporciona momentos de convívio harmonioso para a apreciação da bebida. 
Neste sentido, identifica-se a necessidade de existir um estabelecimento específico para seu consumo e valorização, no qual a apreciação da bebida e o reconhecimento de perfis diferenciados sejam aspectos presentes, buscados e incentivados: o enobar.

Constata-se que o enobar é um espaço que vai além de um simples contato com o vinho antes apreciado, é, ainda, uma forma de acesso e conhecimento sobre a bebida. Um local, como nas tavernas da antiguidade, que, além de proporcionar o vinho, tem uma significação de abrigo que oferece sociabilidade, comida, repouso e diversão.

Por outro lado, verifica-se que no contexto atual brasileiro, o acesso aos enobares ainda é reduzido, visto que a bebida é símbolo de status e diariamente consumida apenas por uma pequena parcela da população.

Destaca-se, nesse contexto, o enobar como espaço para mudança de olhar e local de apropriação do vinho, valorizando-o não somente pela sua singularidade, mas, como bebida que pode ser experienciada, conhecida e apreciada por todos os públicos.

A apropriação de novas tecnologias para o seu desenvolvimento, assim como a flexibilização das taxas nas importações nacionais, são outros exemplos de políticas que reforçam a importância do vinho e procuram permitir aos consumidores maior acesso ao produto.

Por fim, constata-se que os objetivos propostos foram cumpridos, uma vez que a partir dos resultados da pesquisa foi mapeado os enobares da cidade de São Paulo, reconhecendo-os como espaço fundamental para uma nova experimentação e vivência do vinho. Além disso, analisou-se os consumidores/frequentadores deste estabelecimento, categorizando-os conforme seus conhecimentos e envolvimento em atividades destinadas a apreciação da bebida.

Ademais, identificou-se que estes estabelecimentos estavam concentrados principalmente na região sul da cidade de São Paulo o que, de certa forma, limitava o acesso da população que se encontra em outras regiões da cidade.

Desta maneira, o presente estudo mostrou sua relevância ao discutir um tema em certos aspectos inovador e que suscita aprofundamentos numa temática que ganha espaço no cenário atual e desperta novos olhares, atentando-se, não apenas para a bebida ou ao espaço em que ela é consumida, mas principalmente, ao indivíduo que a 
consume e dela se apropria, buscando prazer e interação, além de um convívio amplo em significados e símbolos, tais como os que rodeiam o mundo dos vinhos.

\section{REFERÊNCIAS}

ALGRANTI, L. M. Tabernas e Botequins - Cotidiano e sociabilidades no Rio de Janeiro (1808-1821). Acervo, Rio de Janeiro, v. 24, n. 2, p. 25-42, 2011.

BARRAL, G. L. L. Brasília, espaço de lazer e culturas jovens: o caso de bares. 2006. 133 f. Dissertação (Mestrado em Sociologia Urbana). UnB - Instituto de Ciências Sociais, Brasília. 2006. Digitalizada.

BRAMBILLA, A. Enoturismo e Patrimônio Cultural. In: FÓRUM INTERNACIONAL DA ASSOCIAÇÃO MUNDIAL PARA A FORMAÇÃO EM TURISMO E HOTELARIA - AMFORHT, São Paulo. Resumos... São Paulo: AMFORHT, 2010.

BRASIL. Ministério do Turismo. Inventário da Oferta Turística. Disponível em: <http://www.turismo.gov.br/turismo/programas_acoes/regionalizacao_turismo/inventari o.html>. Acesso em: 19/08/2013.

BUSSOLABAR. História das Tavernas. Disponível em: <http://www.bussolabar.com/historia-das-tabernas.html>. Acesso em: 28/10/2013.

CAMPOS, L. In: Taverna Quando Sumus: A taberna medieval como espaço de prazer e poder. História, imagem e narrativas, Paraná, n. 16, p. 1-20, 2013.

CASTRO, M. Consumo de vinho cresce com o aumento dos apreciadores. Em. Belo Horizonte. 23 jun. 2013. Disponível em:

<http://www.em.com.br/app/noticia/economia/2013/06/23/internas_economia,411244/c onsumo-de-vinho-cresce-com-o-aumento-dos-apreciadores.shtml>. Acesso em: 25/10/2013.

CHARTERS, S.; ALI-KNIGHT, J. Who is the wine tourist? Tourism Management, v. 23. n. 3. p. 311-319, 2002.

CLUBEER. História dos Bares. Disponível em: <http://www.clubeer.com.br/blog/historia-dos-bares/>. Acesso em: 28/10/2013.

COSTA, P. A. S. Análise do perfil do enoturista da região demarcada do Dão. $168 \mathrm{f}$. Dissertação (Mestrado em Gestão e Desenvolvimento em Turismo), Departamento de Economia, Gestão e Engenharia Industrial, Universidade de Aveiro, Aveiro. 2008.

DALLANHOL, E. B.; TONINI, H. Enoturismo. São Paulo: Aleph, 2012. 
DEMO, P. Pesquisa Qualitativa. In: DEMO, P. Metodologia do conhecimento científico. São Paulo: Atlas, 2000, p. 145-159.

DOTT, T.; BIGOTTE, V. Perceptual differences among visitor groups to wineries. Journal of Travel Research, v. 35, n. 3, p. 46-51, 1997.

GETZ, D. Wine tourism: global overview and perspectives on its development. In: DOWLING, R.; CARLSEN, J. Wine tourism - perfect partners. Australian Wine Tourism Conference, Margaret River, Australia, 1998, p. 13-33. Bureau of Tourism Research, Canberra, 1999.

HALL, C. M.; SHARPLES, L.; CAMBOURNE, B.; MACIONIS. N. Wine Tourism around the World: development, management and markets. Oxford: ButterworthHeinemann, 2004.

HALL, C. M.; MITCHELL, R. D. The tourist terroir of New Zealand wine: the importance of region in the wine tourism experience. In: MONTANARI, A. (ed.) Food and Environment: Geographies of Taste. Rome: Società Geografica Italiana, p. 69-91, 2002.

IBRAVIN. Regiões Produtoras. Disponível em:

<http://www.ibravin.com.br/regioesprodutoras.php>. Acesso em: 10/10/2013.

INDICADOR BRASIL. Metade da população brasileira pertence à classe C. Folha de São Paulo. São Paulo. 22 mar. 2012. Disponível em: $<$ http://www.indicadorbrasil.com.br/2012/03/metade-da-populacao-brasileira-pertencea-classe-c/>. Acesso em: 24/10/2013.

JOHNSON, H. The story of Wine. Londres: Mitchell-Beazley, 1989.

INSTITUTO DA VINHA E DO VINHO. Situação Mundial da Vitivinicultura. Fatos e Números. Brasil, n. 6, p. 1-16, 2012.

LEICK, G. Mesopotâmia. A invenção da cidade. Rio de Janeiro: Imago, 2003.

MAGALHÃES, D. M. Consumo e sociabilidades nas tabernas. Estudo preliminar de um caso. Revista da Faculdade de Letras. Sociologia. v. 11, 2001, p. 107-119.

MARTINS, G. A.; THEÓPHILO, C. R. Metodologia da investigação científica para ciências sociais aplicadas. São Paulo: Atlas, 2007.

MELLO, C. E. C. A história do Vinho no Brasil. Revista Adega. [online]. ed. 61. São Paulo: Inner, 2010. Disponível em: <http://revistaadega.uol.com.br/artigo/a-historia-dovinho-no-brasil_2629.html>.

PANOSSO NETTO, A. O que é Turismo. São Paulo: Brasiliense, 2010. 
RODRIGUES, J. M. R. M. A memória e a actualidade das tabernas do concelho de Grândola. 2012. 81 f. Dissertação (Mestrado em Práticas Culturais para Municípios) Faculdade de Ciências Sociais e Humanas, Universidade Nova de Lisboa, Lisboa. 2012.

SÃO PAUlO. São Paulo ponto a ponto. São Paulo: SPTuris - São Paulo Turismo, 2011.

TONINI, H. Estado e Turismo: Políticas Públicas e Enoturismo no Vale dos Vinhedos. 2007. 185 f. Dissertação (Mestrado em Turismo), Programa de Pós-Graduação, Universidade Caxias do Sul, Rio Grande do Sul. 2007.

VINHOS DO BRASIL. Brasil Vitivinícola. Disponível em: <www.vinhosdobrasil.com.br>. Acesso em: 28/10/2013.

WINE INTELLIGENCE. Doing Business In Brazil - Wine Intelligence Report 2013. Disponível em: <http://www.wineintelligence.com/wp-content/uploads/2013/08/DoingBusiness-in-Brazil-2013-Brochure.pdf >. Acesso em: 21/10/2013.

Recebido em: 15-05-2014.

Aprovado em: 13-06-2014. 


\section{APÊNDICE A - ENOBARES DA CIDADE DE SÃO PAULO}

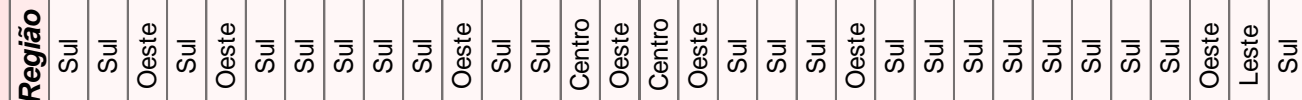

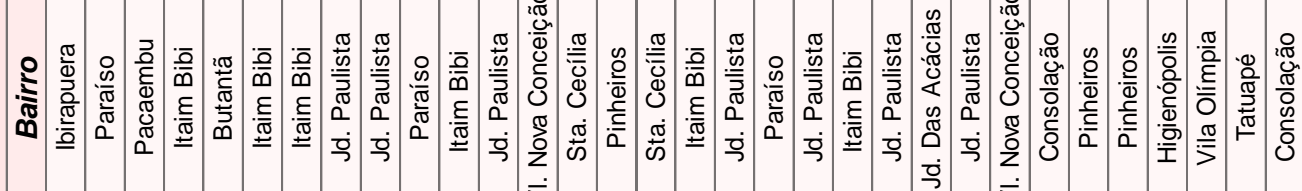

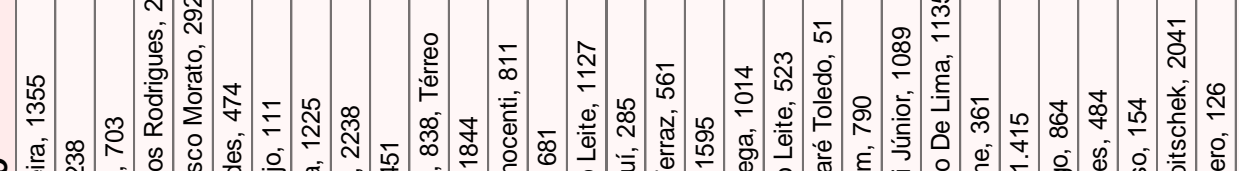

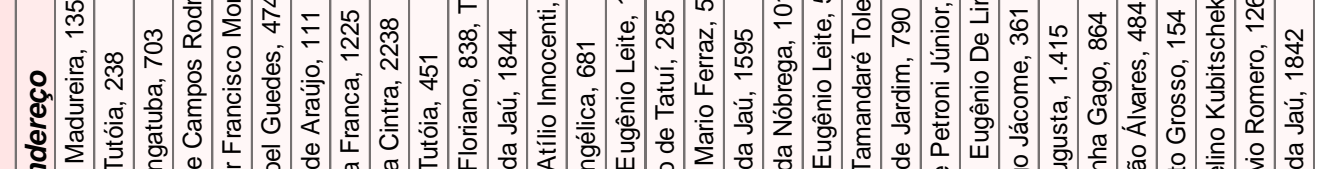

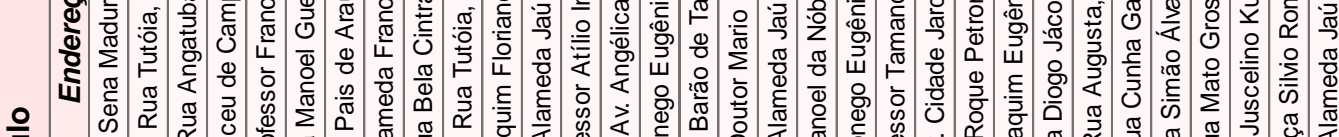

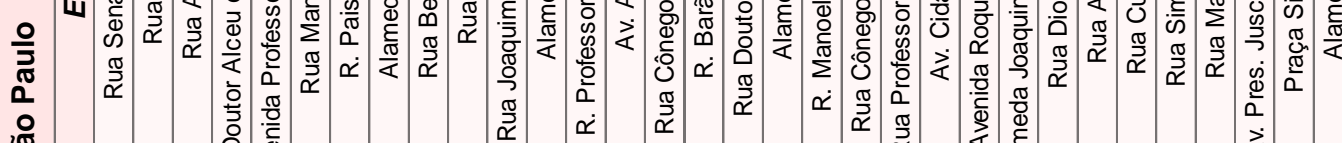

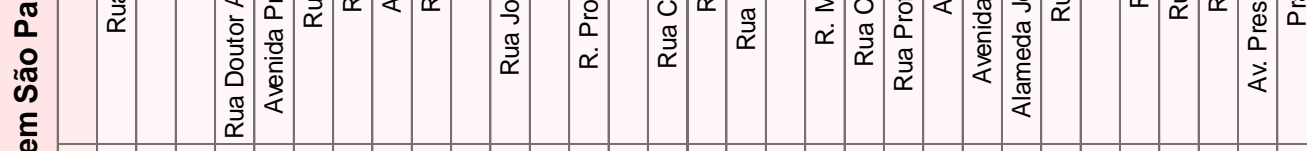

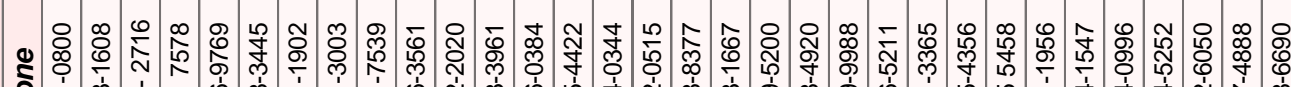

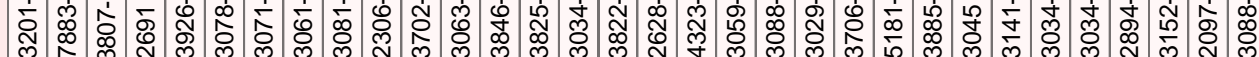

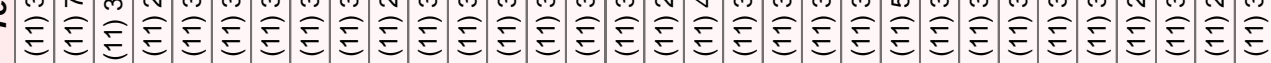

운

$\frac{\pi}{\mathbb{0}}$

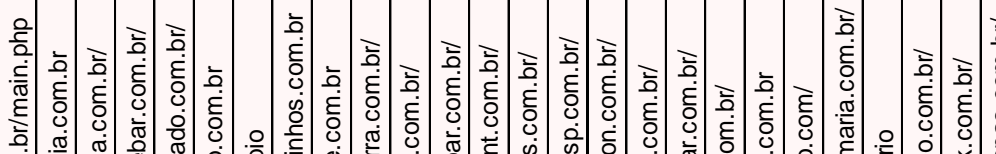

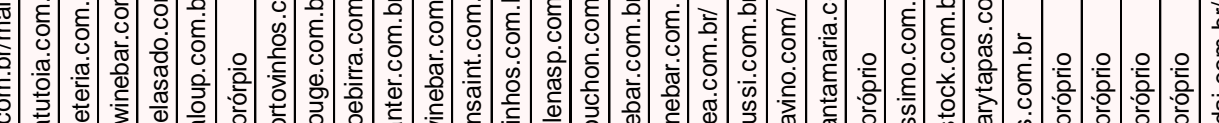

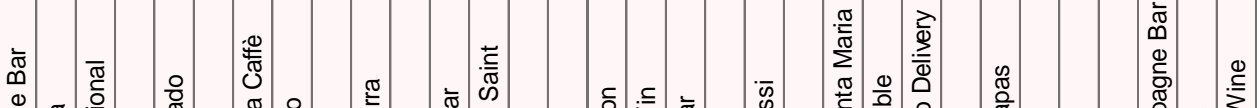

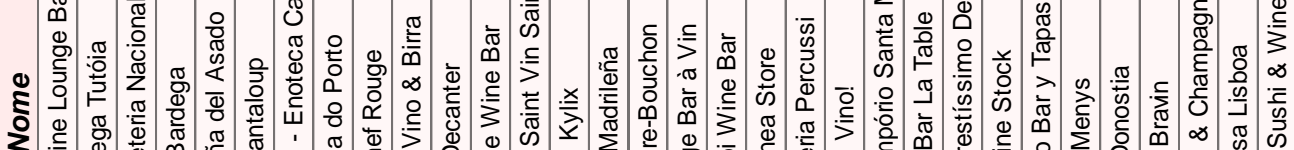

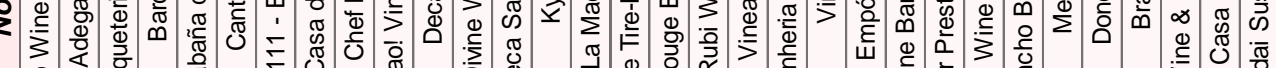




\section{APÊNDICE B - RESULTADOS GERAIS}

\begin{tabular}{|c|c|c|c|c|c|c|}
\hline & \multicolumn{2}{|c|}{ Público Masculino } & \multicolumn{2}{|c|}{ Público Feminino } & \multicolumn{2}{|c|}{ Total } \\
\hline & \begin{tabular}{|l|} 
Número \\
\end{tabular} & Porcentagem & Número & Porcetagem & \begin{tabular}{|l|} 
Número \\
\end{tabular} & Porcentagem \\
\hline Geral & 38 & $63,33 \%$ & 22 & $36,67 \%$ & 60 & $100,00 \%$ \\
\hline \multicolumn{7}{|l|}{ Conhecimento } \\
\hline Grande Conhecedor & 4 & $10,53 \%$ & 0 & $0,00 \%$ & 4 & $6,67 \%$ \\
\hline Conhecedor & 13 & $34,21 \%$ & 7 & $31,82 \%$ & 20 & $33,33 \%$ \\
\hline Conhecedor Limitado & 16 & $42,11 \%$ & 13 & $59,09 \%$ & 29 & $48,33 \%$ \\
\hline Nenhum Conhecimento & 5 & $13,16 \%$ & 2 & $9,09 \%$ & 7 & $36,84 \%$ \\
\hline \multicolumn{7}{|l|}{ Atividades Realizadas } \\
\hline Sócio de Clube de Vinhos & 6 & $15,79 \%$ & 0 & $0,00 \%$ & 6 & $10,00 \%$ \\
\hline Enoturismo & 13 & $34,21 \%$ & 6 & $27,27 \%$ & 19 & $31,67 \%$ \\
\hline Frequenta Enobares & 34 & $89,47 \%$ & 21 & $95,45 \%$ & 55 & $91,67 \%$ \\
\hline Leilões & 1 & $2,63 \%$ & 0 & $0,00 \%$ & 1 & $1,67 \%$ \\
\hline Participa de Confraria & 5 & $13,16 \%$ & 2 & $9,09 \%$ & 7 & $11,67 \%$ \\
\hline Degustações & 26 & $68,42 \%$ & 16 & $72,73 \%$ & 42 & $70,00 \%$ \\
\hline $\begin{array}{c}\text { Palestras, Feiras, Exposições, } \\
\text { Cursos }\end{array}$ & 16 & $42,11 \%$ & 12 & $54,55 \%$ & 28 & $46,67 \%$ \\
\hline Publicações Especializadas & 13 & $34,21 \%$ & 4 & $18,18 \%$ & 17 & $28,33 \%$ \\
\hline $\begin{array}{c}\text { Visita Sites Especializados sobre } \\
\text { Vinhos } \\
\end{array}$ & 21 & $55,26 \%$ & 13 & $59,09 \%$ & 34 & $56,67 \%$ \\
\hline $\begin{array}{l}\text { Outras (Internet;comprar; contato } \\
\text { direto) }\end{array}$ & 11 & $28,95 \%$ & 3 & $13,64 \%$ & 14 & $23,33 \%$ \\
\hline \multicolumn{7}{|l|}{ Atividades Futuras } \\
\hline Sócio de Clube de Vinhos & 9 & $23,68 \%$ & 4 & $18,18 \%$ & 13 & $21,67 \%$ \\
\hline Enoturismo & 16 & $42,11 \%$ & 14 & $63,64 \%$ & 30 & $50,00 \%$ \\
\hline Frequenta Enobares & 11 & $28,95 \%$ & 3 & $13,64 \%$ & 14 & $23,33 \%$ \\
\hline Leilões & 7 & $18,42 \%$ & 3 & $13,64 \%$ & 10 & $16,67 \%$ \\
\hline Participa de Confraria & 10 & $26,32 \%$ & 8 & $36,36 \%$ & 18 & $30,00 \%$ \\
\hline Degustações & 11 & $28,95 \%$ & 11 & $50,00 \%$ & 22 & $36,67 \%$ \\
\hline $\begin{array}{c}\text { Palestras, Feiras, Exposições, } \\
\text { Cursos }\end{array}$ & 8 & $21,05 \%$ & 6 & $27,27 \%$ & 14 & $23,33 \%$ \\
\hline Publicações Especializadas & 4 & $10,53 \%$ & 5 & $22,73 \%$ & 9 & $15,00 \%$ \\
\hline $\begin{array}{l}\text { Visita Sites Especializados sobre } \\
\text { Vinhos }\end{array}$ & 6 & $15,79 \%$ & 3 & $13,64 \%$ & 9 & $15,00 \%$ \\
\hline Outras & 2 & $5,26 \%$ & 0 & $0,00 \%$ & 2 & $3,33 \%$ \\
\hline \multicolumn{7}{|l|}{$\begin{array}{c}\text { Frequência de visitas aos } \\
\text { Enobares }\end{array}$} \\
\hline Mais de 4 vezes & 23 & $60,53 \%$ & 15 & $68,18 \%$ & 44 & $73,33 \%$ \\
\hline De 2 a 4 vezes & 3 & $7,89 \%$ & 4 & $18,18 \%$ & 7 & $10,00 \%$ \\
\hline Uma vez & 1 & $2,63 \%$ & 1 & $4,55 \%$ & 2 & $3,33 \%$ \\
\hline Primeira vez & 4 & $10,53 \%$ & 2 & $9,09 \%$ & 6 & $10,00 \%$ \\
\hline \multicolumn{7}{|l|}{ Motivação } \\
\hline Socializar - Acompanhar & 18 & $47,37 \%$ & 6 & $27,27 \%$ & 24 & $40,00 \%$ \\
\hline Relaxar - Desestressar & 15 & $39,47 \%$ & 6 & $27,27 \%$ & 21 & $35,00 \%$ \\
\hline Comida & 12 & $31,58 \%$ & 8 & $36,36 \%$ & 20 & $33,33 \%$ \\
\hline Bebida & 27 & $71,05 \%$ & 17 & $77,27 \%$ & 44 & $73,33 \%$ \\
\hline Outras & 0 & $0,00 \%$ & 0 & $0,00 \%$ & 0 & $0,00 \%$ \\
\hline \multicolumn{7}{|l|}{ Possui Adega Climatizada } \\
\hline Sim & 17 & $44,74 \%$ & 5 & $22,73 \%$ & 22 & $36,67 \%$ \\
\hline Não & 21 & $55,26 \%$ & 17 & $77,27 \%$ & 38 & $63,33 \%$ \\
\hline \multicolumn{7}{|l|}{ Nível de Interesse } \\
\hline 1 & 0 & $0,00 \%$ & 0 & $0,00 \%$ & 0 & $0,00 \%$ \\
\hline 2 & 3 & $7,89 \%$ & 2 & $9,09 \%$ & 5 & $8,33 \%$ \\
\hline
\end{tabular}




\begin{tabular}{|c|c|c|c|c|c|c|}
\hline 3 & 9 & $23,68 \%$ & 4 & $18,18 \%$ & 13 & $21,67 \%$ \\
\hline 4 & 5 & $13,16 \%$ & 7 & $31,82 \%$ & 12 & $20,00 \%$ \\
\hline 5 & 21 & $55,26 \%$ & 9 & $40,91 \%$ & 30 & $50,00 \%$ \\
\hline Idade & & & & & & \\
\hline até 20 anos & 0 & $0,00 \%$ & 0 & $0,00 \%$ & 0 & $0,00 \%$ \\
\hline de 21 a 30 anos & 7 & $18,42 \%$ & 8 & $36,36 \%$ & 15 & $25,00 \%$ \\
\hline de 31 a 40 anos & 16 & $42,11 \%$ & 6 & $27,27 \%$ & 22 & $36,67 \%$ \\
\hline de 41 a 50 anos & 9 & $23,68 \%$ & 8 & $36,36 \%$ & 17 & $28,33 \%$ \\
\hline de 51 a 60 anos & 4 & $10,53 \%$ & 0 & $0,00 \%$ & 4 & $6,67 \%$ \\
\hline de 61 a 70 anos & 2 & $5,26 \%$ & 0 & $0,00 \%$ & 2 & $3,33 \%$ \\
\hline
\end{tabular}

